\title{
Partner relationships during the transition to parenthood
}

\author{
Barbara Figueiredo $^{\mathrm{a} *}$, Tiffany Field ${ }^{\mathrm{b}, \mathrm{c}}$, Miguel Diego ${ }^{\mathrm{b}}$, Maria Hernandez-Reif ${ }^{\mathrm{d}}$, \\ Osvelia Deeds ${ }^{\mathrm{b}}$ and Angela Ascencio ${ }^{\mathrm{b}}$
}

\begin{abstract}
${ }^{a}$ Department of Psychology, University of Minho, Portugal; ${ }^{b}$ Department of Pediatrics, Touch Research Institutes, University of Miami School of Medicine; ${ }^{c}$ Fielding Graduate University;

${ }^{d}$ University of Alabama
\end{abstract}

\begin{abstract}
Partner relationships are relevant in the psychological adjustment during the transition to parenthood, but mothers have been studied more often than fathers in this respect. The Relationship Questionnaire (RQ) to assess positive and negative dimensions of the partner relationship, the Center for Epidemiological Studies Depression Scale (CES-D) to assess depression and the State Anxiety Inventory (STAI) to assess anxiety were administered to forty-three women and their partners recruited during the second trimester of pregnancy and seen again until after delivery in order to assess differences in women's/men's anxiety and depression according to partner relationships. Results indicate that women $/ \mathrm{men}$ with a less positive relationship with the partner show higher anxiety than women/ men with a more positive partner relationship, and those women/men with a more negative relationship with the partner show both higher depression and higher anxiety than women/men with a less negative relationship with the partner. Also partners of women/men with a more negative partner relationship show higher depression than partners of women/men with a less negative partner relationship. Psychological adjustment during the transition to parenthood of both the women/ men and the partner is impacted by the partner relationship.
\end{abstract}

Keywords: partner relationship; pregnancy; depression; anxiety

\section{Introduction}

Relationships are important for facilitating developmental changes and transitions and for buffering the impact of adverse life events. Relationships might contribute to the individual's psychological adjustment, particularly when the levels of stress, vulnerability and developmental challenge are high, as during the transition to parenthood. However, relationships may also be the context of stressful events, leading consequently to poor health and psychological outcomes.

Pregnancy and the postpartum periods frequently have negative consequences both for the partners' relationship and for the psychological adjustment of both women and men. For example, childbearing women experienced higher level of symptomatology and poor social adjustment during late pregnancy and the early puerperium than nonchildbearing women (O’Hara, Zekoski, Philipps, \& Wright, 1990).

Partner relationships have been noted to decline across pregnancy and the postpartum periods. Decreased proximity and communication and increased conflict and ambivalence between the two members of the couple result in less marital satisfaction and adjustment after compared to before delivery or early pregnancy (Cox, Paley, Burchinal, \& Payne, 1999; Florsheim et al., 2003; Gloger-Tippelt \&

\footnotetext{
*Corresponding author. Email: bbfi@iep.uminho.pt
} 
Huerkamp, 1998; Harwood, McLean, \& Durkin, 2007). Women also report more life stress and less satisfaction with the support they receive postpartum (Goldstein, Diener, \& Mangelsdorf, 1996).

The quality of the partner relationship during the transition to parenthood depends on several factors, including poor relationships with parents during childhood (Florsheim et al., 2003; Rholes, Simpson, Campbell, \& Grich, 2001), parity, and the presence of a psychological disorder either in the individual or in the partner. For example, multipara pregnant women have higher levels of marital dissatisfaction than primipara (Windridge \& Berryman, 1996). In addition, less marital satisfaction has been noted during pregnancy and the postpartum period in depressed women or men, and particularly when the partner is depressed (Feeney, Alexander, Noller, \& Hohaus, 2003; Zelkowitz, \& Milet, 1996).

During the transition to parenthood the relationship and support provided by the partner have been associated with both women's and men's psychological adjustment. The prevalence of psychopathological symptoms during the transition to parenthood is high, especially depression both during pregnancy (Andersson, Sundström-Poromaa, Wulff, Åström, \& Bixo, 2006; Dietz et al., 2007; Marcus, Flynn, Blow, \& Barry, 2003; Westdahl et al., 2007; Wu, Viguera, Riley, Cohen, \& Ecker, 2002) and the postpartum periods (Dietz et al., 2007; Eberhard-Gran, Tambs, Opjordsmoen, Skrondal \& Eskild, 2003; Gorman et al., 2004). Antenatal and postnatal depression in women are associated with poor quality of relationship with the partner (Bernazzani et al., 2004; Diaz, Le, Cooper, \& Muñoz, 2007; Felicea, Salibaa, Grechb, \& Cox, 2004; Simpson, Rholes, Campbell, Tran, \& Wilson, 2003; Westdahl et al., 2007), as well as with perceived lack of social support from the partner (Da Costa, Larouche, Dritsa, \& Brender, 2000; Diaz et al., 2007; Elsenbruch et al., 2007; Seguin, Potvin, St-Denis, \& Loiselle, 1995; Westdahl et al., 2007). Similar results were obtained when prenatal anxiety was addressed (Andersson et al., 2006; Da Costa, Larouche, Dritsa, \& Brende, 1999). Results suggest the importance of considering marital quality and social support in estimations of risk for depression, particularly in immigrant Latina mothers (Diaz et al., 2007). Conflicts, difficulties, lack of support and lack of intimacy in relationships during pregnancy may also lead to psychopathological disorders after delivery (e.g. Collins, DunkelSchetter, Lobel, \& Scrimshaw, 1993; Demyttenaere, Lenaerts, Nijs, \& Van Assche 1995). Interpersonal factors are among the risk factors that predispose women to experiencing mood disturbances during the childbearing years.

Men with poor partner relationships are at risk for depression as much as women during the transition to parenthood (Matthey, Barnett, Ungerer, \& Waters, 2000). Psychopathological symptoms are almost as prevalent in men as in women during pregnancy and the postpartum periods (Areias, Kumar, Barros, \& Figueiredo, 1996a; Dulude, Bélanger, Wright, \& Saburin, 2002; Matthey et al., 2000). The quality of partner relationships during the transition to parenthood is notably as important for men's psychological adjustment as for women's (Areias, Kumar, Barros, \& Figueiredo, 1996b). Symptoms are highly correlated within the couple (Matthey, Barnett, Howie, \& Kavanagh, 2003), and these depend on the quality of their relationship. Also, the men's mental health status impacts on both the quality of the marital relationship and the support provided to the women, which in turn affects women's well being during pregnancy and the postpartum period (e.g. Ritter, Hobfoll, Lavin, Cameron, \& Hulsizer, 2000; Rubertsson, Waldenström, \& Wickberg, 2003). These data highlight the 
relevance of the partner relationship during the transition to parenthood for the wellbeing and the psychological adjustment of the two members of the couple.

Assessing the partner relationship during pregnancy and the postpartum periods may help identify couples who are at risk for psychological maladjustment and who need intervention. The aim of the present study was to study partner relationships during the transition to parenthood, specifically to analyse differences in women and men anxiety and depression according to partner relationships. A second aim was to present the Relationship Questionnaire as a useful measure for assessing partner relationships during pregnancy and the postpartum periods.

\section{Methods}

\section{Participants}

Forty-three pregnant women and their partners (the putative fathers) were recruited during their second trimester of pregnancy (mean $=20$ weeks gestation) and followed until after delivery. They were contacted by a researcher during a prenatal clinic visit for an ultrasound examination at a large urban University Hospital, after expressing their interest to participate. All women who showed interest in participating agreed to take part in the study. Women were excluded from participation in the study if they (1) were less than 18 years old; (2) had multiple foetuses; and (3) reported HIV/ AIDS status or medical complications.

The women were between 18 and 40 years old (mean=27.9), had between $0(57 \%)$ and 4 previous children, and $75 \%$ of the women had less than a college degree. The women were predominantly low $(43 \%)$ to middle $(50 \%)$ socioeconomic status (Hollingshead Two-factor Index of Social Status), and their ethnicity was distributed $59 \%$ Hispanic, 35\% Black-American and 6\% White-American. Only 22\% of the samples were born in the US. Forty-three per cent of the mothers were not happy when they found out that they were pregnant, and $51 \%$ of them reported having a stressful situation during the pregnancy.

\section{Procedures}

The women and men who expressed interest in participating in this study were asked to sign an informed consent. Then they were interviewed to obtain demographic data and to complete the Relationship Questionnaire as well as the Center for Epidemiological Studies-Depression scale (CES-D) (Radloff, 1977) and the State Anxiety Inventory (STAI) (Spielberg, Gorsuch, \& Lushene, 1970) during the second pregnancy trimester (mean $=20$ weeks gestation). They were then asked to return to our lab during the third trimester (mean $=32$ weeks) gestation and after delivery (mean $=14$ days) to repeat these assessments. Seventy-six per cent of the 57 women and their partners who were contacted during the second trimester of pregnancy remained in the study after delivery and were included in the analyses.

\section{Instruments}

The Relationship Questionnaire (RQ) is comprised of 12 items on a 4-point Likert scale (see appendix for questionnaire). The questionnaire was designed for this study to assess positive and negative aspects of the partner relationship: (1) positive 
dimensions, as assessed by the positive relationship subscale, include a sense of support and care, as well as affection, closeness and joint interests and activities; and (2) negative dimensions, as assessed by the negative relationship subscale, include anxiety, irritability and criticisms that have been associated with undesirable outcomes. ${ }^{1}$ A higher score on the positive relationship subscale means that these positive relationship aspects are more present, as well as having a higher score in the negative relationship subscale means that these negative relationship aspects are more present in the partner relationship. Also, the higher the RQ total score the better the partner relationship, as assessed by the participant.

The questionnaire showed a good internal consistency (with a Cronbach Alpha of 0.79 for the total scale, 0.90 for the positive sub-scale and 0.72 for the negative sub-scale) and test-retest reliability ( $r=0.74$ for the total scale).

The Center for Epidemiological Studies Depression Scale (CES-D) is a 20-item scale that assesses the frequency of depressive symptoms within the last week. With scores ranging from 0 and 60, a cut-off of 16 is used for classifying a major depressive episode. With only a $6 \%$ false positive and $36 \%$ false negative rate (Myers \& Weissman, 1980), this scale has been shown to be reliable and valid for diverse demographic groups (Radloff, 1977) and has been successfully used as a self-report assessment of depression in a number of studies that involved similar populations (e.g. Diego et al., 2004).

The State Anxiety Inventory (STAI) is comprised of 20 items and assesses the intensity of anxiety symptoms. The scores range from 20 to 90, and the cutoff for high anxiety is 48. Research has demonstrated that the STAI has adequate concurrent validity and internal consistency (Spielberg et al., 1970), and the scale has been used in several studies with pregnant women (e.g. Da Costa et al., 2000).

\section{Results}

\section{Differences on $R Q$ scores in terms of demographics}

No effects were noted for parity [with primipara women obtaining similar positive $($ mean $=27.7 / 26.5, t=0.79, n s)$ and negative (mean $=17.2 / 17.9, t=0.47, n s)$ RQ scores as multipara women], and for socioeconomic status [with participants from low SES having similar positive $($ mean $=27.9 / 28.4, t=0.88, n s)$ and negative $($ mean $=17.5 / 16.6$, $t=0.62, n s)$ scores as participants from middle SES]. However, participants with more years of school had higher RQ scores on the positive subscale (mean $=29.9$ / 24.2, $t=0.36, p=0.01$ ) than participants with fewer years of school. Participants living with their partner had higher RQ total scores $($ mean $=35.9)$ than participants who were not living with their partner (mean $=30.7, t=3.34, p=0.05)$. Women who were happy when they found out they were pregnant also had higher positive RQ scores $($ mean $=28.1)$ than women who were not happy with their pregnancy (mean $=24.4, t=2.26, p=0.03$ ), although they did not differ on negative RQ scores (mean $=16.7 / 16.3, t=0.17, n s)$.

\section{Differences and correlations on $R Q$ scores between women and men}

Differences and correlations between women and men in RQ scores were computed. No significant differences were obtained on independent sample $t$ tests between the men and women. Correlations between the women's and the men's answers to the 
questionnaire were not significant either, except for the items 'sharing activities' $(r=0.44, p=0.05)$ and 'showing affection to each other' $(r=0.52, p=0.01)$.

Differences on $R Q$ scores between the second and the third trimester of pregnancy and between the third trimester of pregnancy and 1-4 weeks after the delivery

Differences between the second and the third trimester of pregnancy and between the third trimester of pregnancy and 1-4 weeks after the delivery in RQ scores were computed by paired sample $t$ tests. Differences on the item irritable and the negative RQ scores suggested that the participants were more irritable during the third $($ mean $=2.0)$ than the second trimester of pregnancy $($ mean $=1.7, t=3.19, p=0.001)$; they also were more irritable $(t=2.34, p=0.05)$ and had higher negative RQ scores $(t=2.81, p=0.05)$ after the delivery $($ mean $=2.2$, mean $=9.3)$ than during the last trimester of pregnancy $($ mean $=1.7$, mean $=8.31)$.

\section{Differences on depression and anxiety scales as a function of scoring high and low on positive and negative $R Q$ subscales}

Independent sample $t$ tests were used to test differences in terms of depression and anxiety and partner's depression and anxiety between groups of women/men with low and high positive RQ scores and between groups of women/men with low and high negative RQ scores. High and low groups were determined by a quartile split (bottom and top 25\%).

The results presented in Table 1 show that the women/men with low positive RQ scores had higher anxiety scores than the women/men with high positive RQ scores. The women/men with high negative RQ scores had both high depression scores and high anxiety scores. As can also be seen, participants with high negative RQ scores had partners with high depression scores as opposed to the women/men with low negative RQ scores.

Table 1. Independent sample $t$-tests between two groups with high and low positive and between two groups with high and low negative relationship scores, in terms of depression and anxiety and in terms of partner's depression and anxiety.

\begin{tabular}{|c|c|c|c|c|c|c|c|c|c|}
\hline & & \multicolumn{6}{|c|}{ Participant (women/men) } & \multirow[b]{3}{*}{$t$} & \multirow[b]{3}{*}{$p$} \\
\hline & & \multicolumn{2}{|c|}{$\begin{array}{l}\text { Positive } \\
\text { subscale }\end{array}$} & \multirow[b]{2}{*}{$t$} & \multirow[b]{2}{*}{$p$} & \multicolumn{2}{|c|}{$\begin{array}{l}\text { Negative } \\
\text { subscale }\end{array}$} & & \\
\hline & & $\begin{array}{c}\text { Low } \\
(<24) \\
(n=15) \\
\text { Mean } \\
(\mathrm{SD})\end{array}$ & $\begin{array}{c}\text { High } \\
(>30) \\
(n=16) \\
\text { Mean } \\
(\mathrm{SD})\end{array}$ & & & $\begin{array}{c}\text { Low } \\
(<15) \\
(n=15) \\
\text { Mean } \\
(\mathrm{SD})\end{array}$ & $\begin{array}{c}\text { High } \\
(>19) \\
(n=20) \\
\text { Mean } \\
(\mathrm{SD})\end{array}$ & & \\
\hline \multirow[t]{2}{*}{$\begin{array}{l}\text { Participant } \\
\text { (women/men) }\end{array}$} & CESD & $\begin{array}{l}14.73 \\
(8.47)\end{array}$ & $\begin{array}{l}11.13 \\
(6.70)\end{array}$ & 1.32 & & $\begin{array}{c}9.40 \\
(7.14)\end{array}$ & $\begin{array}{l}15.65 \\
(8.72)\end{array}$ & -2.26 & $*$ \\
\hline & STAI & $\begin{array}{l}43.63 \\
(9.32)\end{array}$ & $\begin{array}{l}34.50 \\
(8.91)\end{array}$ & 2.79 & $* *$ & $\begin{array}{c}32.13 \\
(6.90)\end{array}$ & $\begin{array}{c}39.40 \\
(9.62)\end{array}$ & -3.03 & $* *$ \\
\hline \multirow[t]{2}{*}{$\begin{array}{l}\text { Partner's } \\
\text { participant }\end{array}$} & CESD & $\begin{array}{l}14.64 \\
(7.78)\end{array}$ & $\begin{array}{l}14.93 \\
(8.67)\end{array}$ & -0.09 & & $\begin{array}{c}8.77 \\
(5.45)\end{array}$ & $\begin{array}{l}16.50 \\
(9.19)\end{array}$ & -2.48 & $*$ \\
\hline & STAI & $\begin{array}{l}39.64 \\
(8.60)\end{array}$ & $\begin{array}{c}39.60 \\
(10.01)\end{array}$ & 0.01 & & $\begin{array}{c}34.54 \\
(9.00)\end{array}$ & $\begin{array}{c}38.93 \\
(9.59)\end{array}$ & -1.32 & \\
\hline
\end{tabular}

$* * p<0.01 ; * p<0.05$. 


\section{Discussion}

Participants living together or happy with the pregnancy had better partner relationship scores than participants living without their partner or not happy about their pregnancy. Similar data have been reported by others (e.g. Cox et al., 1999), and suggest that the relationship with the partner during the transition to parenthood is affected by the fact that the women/men are living or not living together and are happy or not happy with their pregnancy, two dimensions that need to be evaluated when screening parents for early interventions.

No significant differences were observed between women's and men's scores in terms of how they assessed the quality of their relationship, in agreement with previous results suggesting no differences between men and women in their marital adjustment scores during the transition to parenthood (e.g. Goldberg, Michaels, \& Lamb, 1985). These results also suggest that the RQ is a valid instrument for both women and men.

Increased irritability was reported from the second to the third trimester of pregnancy, and both the irritability and the negative subscale scores increased between the second trimester and the postpartum period. These results are consistent with the decreasing relationship quality noted across pregnancy and the postpartum period by others (e.g. Florsheim et al., 2003; Harwood et al., 2007).

Finally, the pregnant women/men with low positive relationship scores had higher anxiety levels, and the women/men with high negative relationship scores had both higher anxiety and depression levels, as has been found in the literature (e.g. Bernazzani et al., 2004; Da Costa et al., 2000; Matthey et al., 2000). Also, the partners of the women/men with high negative relationship scores had higher depression levels, consistent with other data in the literature (e.g. Feeney et al., 2003).

These results provide additional empirical support to increased anxiety and depression during the transition to parenthood in men and women who perceive their relationship as negative (e.g. Elsenbruch et al., 2007; Westdahl et al., 2007). The quality of the partner relationship impacts on the levels of anxiety and depression, as well as the levels of anxiety and depression affecting the quality of the partner relationship, in both the women/men and the partner (e.g. Feeney et al., 2003; Zelkowitz \& Milet, 1996). Both members of the couple need to be supported while the partner relationship is difficult during the transition to parenthood, in order to prevent/remediate psychological stresses that may consequently occur in both. That seems to be particularly the case when partners are not living together and/or are not happy about their pregnancy, and to be relevant to prevent anxiety and depression particularly in Latino immigrants, as suggested by others (Diaz et al., 2007). In addition, the relationship with and the partner need to be an intervention priority when the women/ men are anxious or depressed during pregnancy and/or the postpartum periods.

The principal limitation of this study is the large number of variables that were simultaneously tested on a small sample. None the less, the Relationship Questionnaire may be a useful measure for identifying couples at risk for poor pregnancy and early parenting outcomes.

\section{Acknowledgements}

We would like to thank the couples that participated in this study and the researchers (Yanexy Vera and Karla Gil) who assisted with the study. This research was supported by grants from 
the March of Dimes (12FY03-48) and NIMH (MH\# 46586) and NIMH Research Scientist Awards (MH\# 00331 and AT\# 001585) to Tiffany Field, funding from Johnson \& Johnson to the Touch Research Institutes, and a grant from the Portuguese Foundation for Science and Technology (POCI/SAU-ESP/56397/2004) to Barbara Figueiredo.

\section{Note}

1. The 12 items of the Relationship Questionnaire were subjected to a principal components analysis (PCA) using SPSS 11.5. The Kaiser-Meyer-Oklin value was 0.67, exceeding the recommended value of 0.6 , and the Bartlett's test of sphericity (Chi-Square $(66)=218,876$, $p<0.001)$ reached statistical significance, supporting the factorability of the correlation matrix. The PCA revealed the presence of three components with eighteen values exceeding 1 , explaining $64.7 \%$ of the variance (component $1=39.2 \%$, component $2=16.6 \%$ and component $3=8.9 \%$ ). An inspection of the screen plot revealed a clear break after the second component, so we decided to retain these two components for further investigation. To aid in the interpretation of these two components a varimax rotation was applied. The rotated solution presented a single structure with both components showing a number of strong loadings and high communalities values. The two-factor solution explained $55.9 \%$ of the variance, with component 1 (positive sub-scale: items $1,2,3,4,6,7,8,9$ ) contributing to $38.7 \%$ of the variance and component 2 (negative sub-scale: items $5,10,11,12$ ) contributing to $17.2 \%$ of the variance.

\section{References}

Andersson, L., Sundström-Poromaa, I., Wulff, M., Åström, M., \& Bixo, M. (2006). Depression and anxiety during pregnancy and six months postpartum: A follow-up study. Acta Obstetricia et Gynecologica Scandinavica, 85(8), 937-944.

Areias, E., Kumar, R., Barros, H., \& Figueiredo, E. (1996a). Comparative incidence of depression in women and men, during pregnancy and after childbirth: Validation of the Edinburgh Postnatal Depression Scale in Portuguese mothers. British Journal of Psychiatry, $169,36-44$.

Areias, E., Kumar, R., Barros, H., \& Figueiredo, E. (1996b). Correlates of postnatal depression in mothers and fathers. British Journal of Psychiatry, 169, 45-52.

Bernazzani, O., Conroy, S., Marks, M., Siddle, K., Guedeney, N., \& Bifulco, A., et al. (2004). Contextual Assessment of the Maternity Experience (CAME): Development of an instrument for cross-cultural research. British Journal of Psychiatry, 184, 20-32.

Collins, N.L., Dunkel-Schetter, C., Lobel, M., \& Scrimshaw, S.C.M. (1993). Social support in pregnancy: Psychosocial correlates of birth outcomes and postpartum depression. Journal of Personality and Social Psychology, 65(6), 1243-1258.

Cox, M.J., Paley, B., Burchinal, M., \& Payne, C.C. (1999). Marital perceptions and interactions and the transition to parenthood. Journal of Marriage and Family, 61, 611-625.

Da Costa, D., Larouche, J., Dritsa, M., \& Brender, W. (1999). Variations in stress levels over de course of pregnancy: Factors associated with elevated hassles, state anxiety and pregnancy-specific anxiety. Journal of Psychosomatic Research, 47, 609-621.

Da Costa, D., Larouche, J., Dritsa, M., \& Brender, W. (2000). Psychological correlates of prepartum and postpartum depressed mood. Journal of Affective Disorders, 59, 31-40.

Demyttenaere, K., Lenaerts, H., Nijs, P., \& Van Assche, F.A. (1995). Individual coping style and psychological attitudes during pregnancy predict depression levels during pregnancy and during postpartum. Acta Psychiatrica Scandinavica, 91, 95-102.

Diaz, M.A., Le, H.N., Cooper, B.A., \& Muñoz, R.F. (2007). Interpersonal factors and perinatal depressive symptomatology in a low-income Latina sample. Cultural Diversity and Ethnic Minorities Psychology, 13(4), 328-336. 
Diego, M., Field, T., Hernandez-Reif, M., Cullen, C., Schanberg, S., \& Kuhn, C. (2004). Prepartum, postpartum and chronic depression effects on newborns. Psychiatry, 67, 63-80.

Dietz, P.M., Williams, S.B., Callaghan, W.M., Bachman, D.J., Whitlock, E.P., \& Hornbrook, M.C. (2007). Clinically identified maternal depression before, during, and after pregnancies ending in live births. American Journal of Psychiatry, 164(10), 1515-1520.

Dulude, D., Bélanger, C., Wright, J., \& Saburin, S. (2002). High-risk pregnancies, psychological distress, and dyadic adjustment. Journal of Reproductive and Infant Psychology, 20(2), 101-124.

Eberhard-Gran, M., Tambs, K., Opjordsmoen, S., Skrondal, A., \& Eskild, A. (2003). A comparison of anxiety and depressive symptomatology in postpartum and non-postpartum mothers. Social Psychology and Psychological Epidemiology, 38, 551-556.

Elsenbruch, S., Benson, S., Rücke, M., Rose, M., Dudenhausen, J., \& Pincus-Knackstedt, M.K., et al. (2007). Social support during pregnancy: Effects on maternal depressive symptoms, smoking and pregnancy outcome. Human Reproduction, 22(3), 869-877.

Feeney, J., Alexander, R., Noller, P., \& Hohaus, L. (2003). Attachment insecurity, depression, and the transition to parenthood. Personal Relationship, 10, 475-493.

Felicea, E., Salibaa, J., Grechb, V., \& Cox, J. (2004). Prevalence rates and psychosocial characteristics associated with depression in pregnancy and postpartum in Maltese women. Journal of Affective Disorders, 82, 297-301.

Florsheim, P., Emi, S., McCann, C., Matthew, W., Ritsuko, F., \& Trina, S., et al. (2003). The transition to parenthood among young African American and Latino couples: Relational predictors of risk for parental dysfunction. Journal of Family Psychology, 17, 65-79.

Gloger-Tippelt, G.S. \& Huerkamp, M. (1998). Relationship change at the transition to parenthood and security of infant-mother attachment. International Journal of Behavior and Development, 22, 633-655.

Goldberg, W.A., Michaels, G.Y., \& Lamb, M.E. (1985). Husbands' and wives' adjustment to pregnancy and first parenthood. Journal of Family Issues, 6, 483-503.

Goldstein, L., Diener, M., \& Mangelsdorf, S. (1996). Maternal characteristics and social support across the transition to motherhood: Associations with maternal behavior. Journal of Family Psychology, 10(1), 60-71.

Gorman, L., O’Hara, M., Figueiredo, B., Hayes, S., Jaquemain, F., \& Klier, C., et al. (2004). Adaptation of the Structured Clinical Interview for DSM-IV disorder for assessing depression in women during pregnancy and postpartum across countries and cultures. British Journal of Psychiatry, 184, 18-25.

Harwood, K., McLean, N., \& Durkin, K. (2007). First-time mothers' expectations of parenthood: What happens when optimistic expectations are not matched by later experiences? Developmental Psychology, 43(1), 1-12.

Marcus, S., Flynn, H., Blow, F., \& Barry, K. (2003). Depressive symptoms among pregnant women screened in obstetrics settings. Journal of Women's Health, 12, 373-380.

Matthey, S., Barnett, B., Ungererm, J., \& Waters, B. (2000). Paternal and maternal depressed mood during the transition to parenthood. Journal of Affective Disorders, 60, 75-85.

Matthey, S., Barnett, B., Howie, P., \& Kavanagh, D. (2003). Diagnosing postpartum depression in mothers and fathers: Whatever happened to anxiety? Journal of Affective Disorders, 74, 139-147.

Myers, J.K. \& Weissman, M.M. (1980). Use of a self-report symptom scale to detect depression in a community sample. American Journal of Psychiatry, 137, 1081-1084.

O’Hara, M.W., Zekoski, E.M., Philipps, L.H., \& Wright, E.J. (1990). Controlled prospective study of postpartum mood disorders: Comparison of childbearing and nonchildbearing women. Journal of Abnormal Psychology, 99(1), 3-15.

Radloff, L. (1977). The CES-D Scale: A self-report depression scale for research in the general population. Applied Psychological Measures, 3, 385-401. 
Rholes, W.S., Simpson, J.A., Campbell, L., \& Grich, J. (2001). Adult attachment and the transition to parenthood. Journal of Personality and Social Psychology, 81, 421-435.

Ritter, C., Hobfoll, S., Lavin, J., Cameron, R., \& Hulsizer, M. (2000). Stress, psychosocial resources, and depressive symptomatology during pregnancy in low-income, inner-city women. Health Psychology, 19(6), 576-585.

Rubertsson, C., Waldenström, U., \& Wickberg, B. (2003). Depressive mood in early pregnancy: Prevalence and women at risk in a national Swedish sample. Journal of Reproductive and Infant Psychology, 21(2), 113-123.

Seguin, L., Potvin, L., St-Denis, M., \& Loiselle, J. (1995). Chronic stressors, social support, and depression during pregnancy. Obstetric and Gynecology, 85(4), 563-589.

Simpson, J., Rholes, S., Campbell, L., Tran, S., \& Wilson, C. (2003). Adult attachment style, the transition to parenthood, and depressive symptoms. Journal of Personality and Social Psychology, 84, 1172-1187.

Spielberg, C., Gorsuch, R.L., \& Lushene, R.E. (1970). The State Trait Anxiety Inventory. Paolo Alto, CA: Consulting Psychology Press.

Westdahl, C., Milan, S., Magriples, U., Kershaw, T.S., Rising, S.S., \& Ickovics, J.R. (2007). Social support and social conflict as predictors of prenatal depression. Obstetric and Gynaecology, 110(1), 134-140.

Windridge, K.C. \& Berryman, J.C. (1996). Maternal adjustment and maternal attitudes during pregnancy and early motherhood in women of 35 and over. Journal of Reproduction and Infant Psychology, 14, 45-55.

Wu, J., Viguera, A., Riley, L., Cohen, L., \& Ecker, J. (2002). Mood disturbance and the mode of delivery. American Journal of Obstetrics and Gynecology, 187, 864-867.

Zelkowitz, P. \& Milet, T.H. (1996). Postpartum psychiatric disorders: Their relationship to psychological adjustment and marital satisfaction in the spouses. Journal of Abnormal Psychology, 105(2), 281-285.

\section{APPENDIX}

\section{2 questions about my relationship with my partner}

This questionnaire concerns how you feel about your relationship with your partner, and takes about 3 minutes to complete. All the information you give is confidential. There are no right or wrong answers - just reply in the way you think best describes your relationship.

\begin{tabular}{|c|c|c|c|c|}
\hline \multirow[b]{2}{*}{ 1. Do you share activities that are of interest for both, you and your partner? } & \multicolumn{2}{|c|}{ NEVER } & \multicolumn{2}{|c|}{ ALWAYS } \\
\hline & 1 & 2 & 3 & 4 \\
\hline 2. When you need help does your partner help you, as you would like him to? & 1 & 2 & 3 & 4 \\
\hline 3. Is your partner always on your side? & 1 & 2 & 3 & 4 \\
\hline 4. Do you and your partner show affection to each other? & 1 & 2 & 3 & 4 \\
\hline 5. Do you argue with your partner? & 1 & 2 & 3 & 4 \\
\hline 6. Does your partner care and worry about you? & 1 & 2 & 3 & 4 \\
\hline 7. Do you and your partner have a lot of fun when you are together? & 1 & 2 & 3 & 4 \\
\hline 8. When something goes wrong, does your partner come and give you assistance? & 1 & 2 & 3 & 4 \\
\hline 9. Do you tell everything to your partner? & 1 & 2 & 3 & 4 \\
\hline 10. Do you feel upset when your partner is away from you? & 1 & 2 & 3 & 4 \\
\hline 11. Do you and your partner get irritable with each other? & 1 & 2 & 3 & 4 \\
\hline 12. Does your partner usually criticise you? & 1 & 2 & 3 & 4 \\
\hline
\end{tabular}

